\title{
Iron intakes of Australian infants and toddlers: findings from the Melbourne Infant Feeding, Activity and Nutrition Trial (InFANT) Program
}

\author{
Linda A. Atkins, Sarah A. McNaughton, Karen J. Campbell and Ewa A. Szymlek-Gay* \\ School of Exercise and Nutrition Sciences, Centre for Physical Activity and Nutrition Research, Deakin University, \\ 221 Burwood Highway, Burwood, VIC 3125, Australia \\ (Submitted 10 June 2015 - Final revision received 28 September 2015 - Accepted 1 October 2015 - First published online 17 November 2015)
}

\section{Abstract}

Fe deficiency remains the most common nutritional deficiency worldwide and young children are at particular risk. Preventative food-based strategies require knowledge of current intakes, sources of Fe, and factors associated with low Fe intakes; yet few data are available for Australian children under 2 years. This study's objectives were to determine intakes and food sources of Fe for Australian infants and toddlers and identify non-dietary factors associated with Fe intake. Dietary, anthropometric and socio-demographic data from the Melbourne Infant Feeding, Activity and Nutrition Trial Program were analysed for 485 infants (mean age: 9.1 (sD 1.2) months) and 423 toddlers (mean age: $19 \cdot 6$ (sD 2.6) months) and their mothers. Dietary intakes were assessed via 24-h recalls over 3 non-consecutive days. Prevalence of inadequate Fe intake was estimated using the full probability approach. Associations between potential non-dietary predictors (sex, breast-feeding status, age when introduced to solid foods, maternal age, maternal education, maternal employment status and mother's country of birth) and Fe intakes were assessed using linear regression. Mean Fe intakes were 9.1 (SD 4.3) mg/d for infants and 6.6 (SD 2.4) mg/d for toddlers. Our results showed that $32.6 \%$ of infants and $18.6 \%$ of toddlers had inadequate Fe intake. Main food sources of Fe were Fe-fortified infant formula and cereals for infants and toddlers, respectively. Female sex and current breast-feeding were negatively associated with infant Fe intakes. Introduction to solid foods at or later than 6 months was negatively associated with Fe intake in toddlers. These data may facilitate food-based interventions to improve Australian children's Fe intake levels.

\section{Key words: Iron intake: Infants: Toddlers: Dietary intakes: 24-h recall}

Globally, Fe deficiency is the most common nutritional deficiency, affecting many population groups, with young children among the most vulnerable ${ }^{(1,2)}$. In Australia, Fe deficiency is the leading risk factor for the burden of disease in children under 5 years of age ${ }^{(3)}$. In fact, biochemical evidence shows that up to $30 \%$ of Australian infants and toddlers are at risk for $\mathrm{Fe}$ deficiency ${ }^{(4-7)}$. This is of public health concern because, in early childhood, Fe deficiency that progresses to Fe deficiency anaemia has been shown to limit neuro-behavioural proces$\operatorname{sing}^{(8,9)}$ and pose a serious threat to long-term development ${ }^{(10-12)}$. Longitudinal studies on the cognitive impairment in children as a result of early Fe-deficiency anaemia have shown continued developmental delay, despite subsequent $\mathrm{Fe}$ repletion ${ }^{(11,13)}$. Although limited, evidence suggests that $\mathrm{Fe}$ deficiency without anaemia in early childhood may also be detrimental to future cognitive and behavioural performance ${ }^{(14,15)}$, especially if deficiency is concurrent with critical developmental stages ${ }^{(16)}$. Prevention of Fe deficiency in the early years of life is, therefore, important in order to avoid its serious and potentially irreversible effects.
The second half of infancy (ages 6-12 months) is characterised by rapid growth and blood volume expansion, which coincide with exhausted fetal $\mathrm{Fe}$ stores $^{(17)}$. As a result, $\mathrm{Fe}$ requirements per $\mathrm{kg}$ of body weight are greater during this time than at any other time of life ${ }^{(17,18)}$. However, infants and toddlers are unlikely to meet their Fe requirements because during the second half of infancy children transition from predominantly milk-based diets to diets based on family foods, which are often poor in $\mathrm{Fe}^{(19,20)}$. It is therefore important to develop population-based interventions aimed at improving $\mathrm{Fe}$ intakes, thus reducing the risk of Fe deficiency in this population. To design appropriately targeted interventions, it is necessary to clearly understand likely determinants of poor $\mathrm{Fe}$ intakes, both dietary and non-dietary. Studies that have investigated the adequacy of Fe intakes or food sources of $\mathrm{Fe}$ in Australian children under 24 months of age are scarce ${ }^{(5,20-24)}$. Furthermore, few published studies report non-dietary determinants of Fe intake for this age group ${ }^{(25,26)}$, and none within Australia. Therefore, the aims of this study were to determine Fe intakes and food sources of Fe for Australian infants and

\footnotetext{
Abbreviation: InFANT Program, Infant Feeding, Activity and Nutrition Trial (InFANT) Program.
}

* Corresponding author: Dr E. A. Szymlek-Gay, fax +61 39244 6017, email ewa.szymlekgay@deakin.edu.au 
toddlers, and identify the non-dietary factors associated with the Fe intakes of this population.

\section{Methods \\ Study design and participants}

The Melbourne Infant Feeding, Activity and Nutrition Trial (InFANT) Program was a cluster-randomised controlled trial for obesity prevention conducted during 2008-2010 ${ }^{(27)}$. The trial aimed to promote an early start to the development of healthy behaviours by focusing on parenting skills and strategies delivered at group meetings ${ }^{(27)}$. The study design and data collection methods have been described in detail elsewhere ${ }^{(28)}$. Briefly, sixty-two of 103 eligible first-time parents' groups within randomly selected, representative local government areas of Melbourne were recruited during standard group meetings at maternal and child health centres. Attendees were eligible to participate if they were first-time parents, gave informed, written consent and could communicate in English ${ }^{(27)}$. The intervention group was offered six 2 -h dietitian-delivered information sessions regarding infant feeding, diet, physical activity and television viewing, whereas parents of children in the control group received six non-obesity-focused newsletters on other aspects of child development ${ }^{(27)}$. All parents continued to receive usual care from child health nurses ${ }^{(27)}$. Sociodemographic data were collected for 542 infant-carer pairs (representing $86 \%$ of eligible parents) at two time points when the children were approximately 9 and 20 months of age (referred to as infants and toddlers, respectively, throughout this paper). Dietary and anthropometric data were also collected when the children were approximately 9 and 20 months of age. Ethics approval for the InFANT Program was obtained from the Deakin University Human Research Ethics Committee (ID number: EC 175-2007) and the Victorian Government Department of Human Services, Office for Children, Research Coordinating Committee (Ref: CDF/07/1138).

\section{Measures}

Socio-economic and demographic information was obtained from parents via a self-administered questionnaire upon enrolment when infants were approximately 3 months of age ${ }^{(28)}$. Maternal age, pre-pregnancy weight, height, education level, employment status, country of birth, duration of pregnancy, and child age and sex, birth weight and length, breast-feeding status and age when first introduced to solid foods were reported. Maternal BMI was calculated as weight $(\mathrm{kg}) /$ height $\left(\mathrm{m}^{2}\right)^{(29)}$. Children's anthropometric measures (nude weight and recumbent length) were taken by trained staff at approximately 9 and 20 months of age using digital scales (Tanita 1582; Tanita) and a calibrated measuring mat (Seca 210; Seca Deutschland) ${ }^{(27)}$

\section{Dietary intake}

Trained nutritionists conducted three multipass 24-h recalls with a parent of each child via telephone when the children were 9 and 20 months old to assess the children's dietary intake ${ }^{(30)}$.
Telephone calls were unscheduled for $96 \%$ of cases $^{(27)}$. For each child, the recalls were conducted on 3 non-consecutive days, including 1 weekend day. Purpose-designed booklets with photos of portion sizes and examples of measures (cups, bowls, drink containers and spoons) facilitated estimation of food consumption ${ }^{(30)}$. A purpose-designed database was used to code the dietary intake data using standard Australian food composition databases ${ }^{(31)}$. All recalls were checked by a dietitian for accuracy after initial coding. Foods that were consumed by the children but were missing from the Australian food composition databases ${ }^{(31)}$ were added utilising product nutrition information panel data and recipe calculations. Where possible, mixed dishes were disaggregated and entered as individual ingredients based on detailed ingredients and proportion information provided by parents. Breast-feeding was recorded as minutes of time spent breast-feeding and then converted to volume consistent with previous studies ${ }^{(32)}$.

\section{Statistical analysis}

After excluding those with fewer than two recalls ( $n 47$ for infants, $n 113$ for toddlers), main carer listed as father ( $n 1$ for both infants and toddlers), and Fe and energy intakes $>$ or $<3$ SD of the mean ( $n 9$ for infants, $n 5$ for toddlers), dietary data were available for 485 infants at the first data collection point (children aged around 9 months) and for 423 toddlers at the second data collection point (children aged around 20 months). Data from both the intervention and the control group were included in all analyses as there were no statistically significant differences in Fe or energy intakes between groups at 9- or 20-month data collection points (data not shown).

Mean values and standard deviations of daily energy and nutrient intakes, Fe intakes per $1000 \mathrm{~kJ}$, Fe intakes/kg of body weight, and intakes of unmodified cows' milk and animal tissue were calculated for each age group ${ }^{(30,31)}$. The grams of animal tissue for each food were determined as follows. Foods that contained meat only were classified as $100 \%$ animal tissue. For mixed dishes where quantities of ingredients were not provided, estimations were made using equivalent commercially available products. For example, it was determined from product label information that a commercially prepared beef and vegetable risotto infant meal contained $10 \%$ beef. When recipes were not reported by the parents for mixed dishes, recipes in the Australian food composition database ${ }^{(31)}$ were used to determine meat content. The proportion of infants and toddlers consuming $>500 \mathrm{ml}$ of unmodified cows' milk was calculated.

The prevalence of inadequate Fe intake was estimated using the full probability approach because the distribution of Fe requirements for children is not symmetrical about the estimated average requirement for $\mathrm{Fe}^{(33,34)}$. With this method, the software PC-SIDE (version 1.0, 2003) was used to adjust the distribution of observed $\mathrm{Fe}$ intake for the day-to-day variability in intake within individuals and calculate the distribution of usual intake for each age group ${ }^{(35)}$. Subsequently, assuming $10 \%$ bioavailability of Fe for infants and $14 \%$ for toddlers ${ }^{(36)}$, the probability of inadequacy of the usual Fe intake for each child in each age group was determined as described before ${ }^{(33)}$, and then these individual probabilities were averaged across 
each age group to estimate the prevalence of inadequate $\mathrm{Fe}$ intake for each group ${ }^{(33,37)}$.

To determine the contributions of Fe from food groups, the 1688 individual food items consumed by children in the InFANT Program were grouped before analysis using the standard food groupings in the AUSNUT 2007 food coding system developed by Food Standards Australia New Zealand (online Supplementary Appendix Table S1) ${ }^{(31)}$. The mean values and standard deviations of $\mathrm{Fe}(\mathrm{g})$ consumed and percentage contribution to total $\mathrm{Fe}$ intake were then calculated for each food group to determine the food sources of Fe. Separate categories were created for intakes of breast milk and infant/toddler formulae. Fe contribution from food groups were also determined for each age group by breast-feeding status, age of introduction to solid foods and sex (online Supplementary Appendix Tables S2-S7).

Breast-feeding status data and socio-demographic factors were investigated for associations with $\mathrm{Fe}$ intakes. Breastfeeding status was categorised as either 'never breast-fed', 'stopped breast-feeding', or 'currently breast-feeding'. Binary variables for age when the child was introduced to solid foods were created using the age of 6 months as a cut-off point based on the Australian infant-feeding guidelines ${ }^{(37)}$. Binary variables for maternal age at recruitment were created using median cut-off points. Maternal education was used as a measure of socio-economic position (categorised as 'low' (up to completion of final year of secondary school), 'medium' (trade certificate or diploma) and 'high' (undergraduate university degree or higher)), rather than current maternal/family income, which may not adequately reflect usual household income because of changes in employment status. Variables for employment status were recoded to reflect potential time commitments outside of parenting duties rather than used as a measure of socioeconomic position and categorised as 'maternity leave/home duties/unemployed', 'employed full-time or part-time/student', or 'other'. The category named 'other' includes a variety of statuses such as casual employment, transitional roles, selfemployment, in receipt of benefits, or undisclosed status. Country of birth was categorised as 'Australia' or 'other'. Linear regression was used to assess the associations between potential non-dietary predictors and $\mathrm{Fe}$ intakes. Predictors that were significantly associated with Fe intakes $(P<0.05)$ were simultaneously entered into multiple linear regression models to identify independent associations. $P$ values were obtained from regression analyses and adjusted for clustering. The distributions of residuals from all models were examined for the purpose of model checking. Statistical analyses were performed using Stata software (Release 12.1 and 13.1; StataCorp LP). All statistical tests were two-sided and $P<0.05$ was considered statistically significant. No adjustments were made for multiple testing.

\section{Results}

\section{Participant characteristics}

The mean age was 9.1 (SD 1.2) and 19.6 (SD 2.6) months for infants and toddlers, respectively (Table 1 ). Birth weights and

Table 1. Characteristics of study participants

(Numbers and percentages; mean values and standard deviations)

\begin{tabular}{|c|c|c|c|c|c|c|c|c|}
\hline \multirow[b]{2}{*}{ Variables } & \multicolumn{4}{|c|}{ Infants } & \multicolumn{4}{|c|}{ Toddlers } \\
\hline & $n^{\star}$ & Mean & SD & $\%$ & $n^{\star}$ & Mean & $\mathrm{SD}$ & $\%$ \\
\hline \multicolumn{9}{|l|}{ Child characteristics } \\
\hline Age (months) & 461 & $9 \cdot 1$ & $1 \cdot 2$ & & 417 & $19 \cdot 6$ & $2 \cdot 6$ & \\
\hline Sex (male) & 485 & & & $52 \cdot 8$ & 423 & & & 54.8 \\
\hline Gestational age (weeks) & 482 & $38 \cdot 8$ & $2 \cdot 4$ & & 422 & 38.7 & 2.5 & \\
\hline Birth weight $(\mathrm{kg})$ & 480 & 3.4 & 0.6 & & 420 & $3 \cdot 4$ & 0.6 & \\
\hline Birth length (cm) & 472 & $50 \cdot 0$ & $2 \cdot 7$ & & 413 & $50 \cdot 0$ & $2 \cdot 8$ & \\
\hline Current weight (kg) & 485 & 8.9 & $1 \cdot 1$ & & 412 & 11.4 & $1 \cdot 3$ & \\
\hline Current length (cm) & 485 & 71.9 & 3.0 & & 412 & $80 \cdot 6$ & 3.4 & \\
\hline Breast-feeding status & 461 & & & & 400 & & & \\
\hline Never breast-fed & 10 & & & $2 \cdot 2$ & 10 & & & 2.5 \\
\hline Stopped breast-feeding & 240 & & & $52 \cdot 1$ & 356 & & & 89.0 \\
\hline Currently breast-feeding & 211 & & & $45 \cdot 8$ & 34 & & & $8 \cdot 5$ \\
\hline Age when introduced to solid foods (months) & 458 & $5 \cdot 3$ & 0.9 & & 403 & $5 \cdot 3$ & 0.9 & \\
\hline$<6$ & 319 & & & $69 \cdot 7$ & 282 & & & $70 \cdot 0$ \\
\hline$\geq 6$ & 139 & & & $30 \cdot 3$ & 121 & & & $30 \cdot 0$ \\
\hline \multicolumn{9}{|l|}{ Maternal characteristics } \\
\hline Age at recruitment (years) & 483 & $32 \cdot 3$ & $4 \cdot 2$ & & 423 & $32 \cdot 4$ & 4.4 & \\
\hline Pre-pregnancy BMI $\left(\mathrm{kg} / \mathrm{m}^{2}\right)$ & 481 & $24 \cdot 6$ & $5 \cdot 3$ & & 422 & 24.5 & $5 \cdot 3$ & \\
\hline Level of education & 483 & & & & 423 & & & \\
\hline Low (syear 12)† & 101 & & & $20 \cdot 9$ & 86 & & & $20 \cdot 3$ \\
\hline Medium (trade/certificate) & 115 & & & $23 \cdot 8$ & 99 & & & $23 \cdot 4$ \\
\hline High ( $\geq$ university degree) & 267 & & & $55 \cdot 3$ & 238 & & & $56 \cdot 3$ \\
\hline Employment status & 461 & & & & 385 & & & \\
\hline Maternity leave/home duties/unemployed & 289 & & & $62 \cdot 7$ & 140 & & & $36 \cdot 4$ \\
\hline Employed full-time or part-time/student & 161 & & & 34.9 & 240 & & & $62 \cdot 3$ \\
\hline Other & 11 & & & 2.4 & 5 & & & $1 \cdot 3$ \\
\hline Born in Australia & 382 & & & $79 \cdot 1$ & 337 & & & $79 \cdot 7$ \\
\hline
\end{tabular}

* $n$ Differs for each variable due to missing data.

$\dagger$ Up to completion of final year of secondary school. 
lengths, gestational lengths and current weights and lengths were within normal ranges ${ }^{(38)}$ for both infants and toddlers. Nearly half of the children were breast-fed at 9 months of age; this decreased to $8.5 \%$ at 20 months. At recruitment, the mean age of mothers was 32.3 (SD 4.2 ) years for the infant group and 32.4 (SD 4.4) years for the toddler group. Most mothers were Australian born and $>50 \%$ were university educated. At 9 months of age, the majority $(62.7 \%)$ of mothers were currently not working, whereas at 20 months of age most mothers (62.3\%) were currently working or studying.

\section{Dietary variables and iron intakes of infants and toddlers}

Mean energy intakes (Table 2) were 3521 (SD 841) kJ/d for infants and 4469 (sD 862) kJ/d for toddlers. Mean Fe intakes were $9 \cdot 1(\mathrm{sD} 4.3) \mathrm{mg} / \mathrm{d}$ for infants and $6 \cdot 6(\mathrm{SD} 2.4) \mathrm{mg} / \mathrm{d}$ for toddlers $(P<0.0001$ for the difference between infants and toddlers). There were $32.6 \%$ of infants (95\% CI 28.4, 36.9\%) and $18.6 \%$ of toddlers ( $95 \%$ CI $15 \cdot 1,22.7 \%$ ) estimated to be at risk for inadequate Fe intake. Infants consumed $20.7 \mathrm{~g}$ of animal tissue/d, whereas toddlers consumed $35.3 \mathrm{~g}$ of animal tissue/d. More than $500 \mathrm{ml}$ of unmodified cows' milk was consumed daily by $1.4 \%$ of infants (range of intakes: $527-700 \mathrm{ml}$ ) and $25.8 \%$ of toddlers (range of intakes: 504-942 ml; data not shown in table).

\section{Contributions of iron from food groups}

The main sources of dietary Fe for infants (Table 3) were infant formula (43.5\%), Fe-fortified infant products $(27 \cdot 6 \%)$, cereals $(13.1 \%)$ and meat, meat products and dishes (5.3\%). For toddlers, cereals were the greatest contributors of $\mathrm{Fe}(43.3 \%)$, followed by meat, meat products and dishes (10.1\%), toddler formula (8.6\%) and fruits (8.5\%). The main sources of Fe did not change for infants or toddlers with age of introduction to solid foods or sex (online Supplementary Appendix Tables S4-S7). The main sources of Fe for currently breast-fed children were Fe-fortified infant products, infant formula and cereals for infants, and cereals, fruit and meat, meat products and dishes for toddlers (online Supplementary Appendix Tables S2 and S3).

\section{Factors associated with iron intakes of infants and toddlers}

Male infants had higher intakes of Fe compared with female infants $(P=0.022)$ (Table 4$)$; however, after adjusting for energy intakes, this difference was no longer significant (data not shown $(P=0.970)$. There was no association between $\mathrm{Fe}$ intake and sex among toddlers $(P=0 \cdot 139)$. Breast-feeding status was associated with $\mathrm{Fe}$ intakes for infants $(P<0 \cdot 001)$, with $\mathrm{Fe}$ intakes lowest for currently breast-feeding infants (mean $6 \cdot 3$ (sD 3.9) $\mathrm{mg} / \mathrm{d}$ ) compared with infants who had never breast-fed (mean $11.4(\mathrm{sD} 3.8) \mathrm{mg} / \mathrm{d}$ ) or had ceased breast-feeding (mean 11.2 ( $\mathrm{SD} 3 \cdot 2) \mathrm{mg} / \mathrm{d}$ ). There was no significant association for toddlers between Fe intakes and breast-feeding status. Toddlers introduced to solid foods earlier than 6 months had higher Fe intakes compared with toddlers introduced to solid foods at or after 6 months of age $(P=0 \cdot 007)$. The time of introduction to solid foods was not associated with infant $\mathrm{Fe}$ intakes $(P=0.462)$. No associations were shown between Fe intake and maternal age at recruitment, maternal education, maternal employment status, or mother's country of birth among infants or toddlers. When sex and breast-feeding status among infants were simultaneously entered into multiple regression models, significant associations with Fe intake remained (all $P<0.05$, data not shown in table).

Table 2. Dietary intakes of children at 9 and 20 months of age

(Mean values and standard deviations; $95 \%$ confidence intervals and 25th, 75th percentile)

\begin{tabular}{|c|c|c|c|c|c|c|c|c|}
\hline \multirow[b]{2}{*}{ Variables } & \multicolumn{4}{|c|}{ Infants ( $n$ 485) } & \multicolumn{4}{|c|}{ Toddlers ( $n$ 423) } \\
\hline & Mean & SD & $\%$ & $\begin{array}{l}95 \% \mathrm{Cl} \text { or } 25 \text { th, } 75 \text { th } \\
\text { percentile }\end{array}$ & Mean & SD & $\%$ & $\begin{array}{l}95 \% \mathrm{Cl} \text { or } 25 \text { th, } 75 \text { th } \\
\text { percentile }\end{array}$ \\
\hline \multicolumn{9}{|l|}{$\overline{\mathrm{Fe}}$} \\
\hline Intake (mg/d) & 9.1 & $4 \cdot 3$ & & & $6 \cdot 6$ & $2 \cdot 4$ & & \\
\hline Density $(\mathrm{mg} / 1000 \mathrm{~kJ}$ per $\mathrm{d})$ & $2 \cdot 6$ & $1 \cdot 1$ & & & 1.5 & 0.5 & & \\
\hline Intake per $\mathrm{kg}$ of body weight $(\mathrm{mg} / \mathrm{kg}$ per $\mathrm{d})$ & 1.0 & 0.5 & & & 0.6 & 0.2 & & \\
\hline Inadequate intake* ${ }^{*}$ & & & $32 \cdot 6$ & $28.4,36.9 \dagger$ & & & 18.6 & $15 \cdot 1,22 \cdot 7 \dagger$ \\
\hline \multicolumn{9}{|l|}{ Other dietary factors } \\
\hline Total energy $(\mathrm{kJ} / \mathrm{d})$ & 3521 & 841 & & & 4469 & 862 & & \\
\hline Protein $(\mathrm{g} / \mathrm{d})$ & 29.9 & $11 \cdot 2$ & & & 47.0 & 12.5 & & \\
\hline Fat $(\mathrm{g} / \mathrm{d})$ & 33.8 & $8 \cdot 3$ & & & 38.1 & $10 \cdot 0$ & & \\
\hline Carbohydrate $(\mathrm{g} / \mathrm{d})$ & $100 \cdot 5$ & 26.4 & & & $129 \cdot 3$ & $28 \cdot 0$ & & \\
\hline Dietary fibre $(\mathrm{g} / \mathrm{d})$ & 8.5 & 4.1 & & & 12.9 & 4.3 & & \\
\hline $\mathrm{Ca}(\mathrm{mg} / \mathrm{d})$ & $645 \cdot 2$ & 248.6 & & & $760 \cdot 7$ & 220.0 & & \\
\hline Vitamin C $(\mathrm{mg} / \mathrm{d})$ & 101.3 & 43.7 & & & $49.8 \ddagger$ & & & $31 \cdot 9,72 \cdot 9 \S$ \\
\hline Cows' milk (g/d) & $0.0 \ddagger$ & & & $0.0,42 \cdot 1 \S$ & 335.4 & 214.5 & & \\
\hline Animal tissue (g/d) & $20.7 \ddagger$ & & & $9 \cdot 1,39.5 \S$ & $35 \cdot 3 \ddagger$ & & & $19 \cdot 7,55.9 \S$ \\
\hline
\end{tabular}

* Percentage of children at risk for inadequate Fe intakes estimated using the full probability approach ${ }^{(33)}$ assuming $10 \%$ bioavailability of Fe for infants and $14 \%$ for toddlers ${ }^{(36)}$ after adjustment of the observed intake distribution to approximate the usual intake distribution for each age group using PC-SIDE (version 1.0, 2003)

$\dagger 95 \% \mathrm{Cl}$

$\ddagger$ Median.

$\S 25$ th, 75th percentile. 
Table 3. Contribution of iron from food groups in the diets of 9- and 20-month-old children

(Mean values, standard deviations and percentages)

\begin{tabular}{|c|c|c|c|c|c|c|}
\hline \multirow[b]{2}{*}{ Food groups } & \multicolumn{3}{|c|}{ Infants ( $n$ 485) } & \multicolumn{3}{|c|}{ Toddlers ( $n$ 423) } \\
\hline & Mean $(\mathrm{mg} / \mathrm{d})$ & SD & $\%^{*}$ & Mean $(\mathrm{mg} / \mathrm{d})$ & SD & $\%^{*}$ \\
\hline Infant and toddler formulae† & 3.9 & 3.3 & 43.5 & 0.6 & 1.6 & 8.6 \\
\hline Breast milk & 0.0 & 0.1 & 0.5 & 0.0 & 0.0 & 0.1 \\
\hline Other infant and toddler products & 2.5 & 3.1 & $27 \cdot 6$ & 0.2 & 0.6 & 3.7 \\
\hline Infant and toddler cereal & $2 \cdot 2$ & 3.0 & 24.4 & $0 \cdot 1$ & 0.6 & $2 \cdot 2$ \\
\hline Infant and toddler food & 0.3 & 0.4 & 3.3 & $0 \cdot 1$ & 0.3 & 1.5 \\
\hline Infant and toddler drink $\ddagger$ & 0.0 & 0.0 & 0.0 & 0.0 & 0.0 & 0.0 \\
\hline Cereals & 1.2 & $1 \cdot 1$ & $13 \cdot 1$ & $2 \cdot 9$ & 1.6 & $43 \cdot 3$ \\
\hline Flours, grains & 0.1 & 0.2 & 0.6 & 0.1 & 0.5 & 1.5 \\
\hline Regular breads, rolls & 0.2 & 0.3 & $2 \cdot 6$ & 0.6 & 0.4 & 9.1 \\
\hline English muffins; flat, sweet or savoury breads & 0.0 & 0.1 & 0.2 & $0 \cdot 1$ & 0.2 & 1.9 \\
\hline Pasta & 0.1 & 0.1 & 0.6 & $0 \cdot 1$ & 0.2 & 1.7 \\
\hline Breakfast cereals, bars§ & 0.8 & 1.0 & 8.9 & 1.9 & 1.6 & $28 \cdot 0$ \\
\hline Porridge breakfasts & 0.0 & 0.1 & 0.2 & 0.1 & 0.2 & $1 \cdot 2$ \\
\hline Other cereal products & 0.1 & 0.2 & 0.9 & 0.3 & 0.4 & 4.9 \\
\hline Sweet biscuits & 0.0 & 0.0 & $0 \cdot 1$ & $0 \cdot 1$ & 0.1 & 0.8 \\
\hline Savoury biscuits & 0.0 & 0.1 & 0.2 & $0 \cdot 1$ & 0.1 & 0.8 \\
\hline Cakes, buns, muffins & 0.0 & 0.1 & 0.1 & 0.0 & 0.1 & 0.7 \\
\hline Pastries & 0.0 & 0.0 & 0.0 & 0.0 & 0.1 & 0.6 \\
\hline Mixed cereal-based dishes & 0.0 & 0.1 & 0.4 & $0 \cdot 1$ & 0.3 & $2 \cdot 0$ \\
\hline Batter-based products & 0.0 & 0.0 & 0.1 & 0.0 & 0.1 & 0.6 \\
\hline Meat, meat products and dishes & 0.5 & 0.6 & $5 \cdot 3$ & 0.7 & 0.6 & $10 \cdot 1$ \\
\hline Meatll & 0.2 & 0.3 & $2 \cdot 2$ & 0.2 & 0.3 & 3.4 \\
\hline Processed meat & 0.0 & 0.1 & 0.2 & 0.1 & 0.2 & 1.5 \\
\hline Meat dishes ${ }^{\star \star}$ & 0.3 & 0.5 & $2 \cdot 9$ & 0.3 & 0.5 & $5 \cdot 2$ \\
\hline Dairy products & 0.1 & 0.1 & 0.8 & 0.3 & 0.6 & $4 \cdot 1$ \\
\hline Cows' milk & 0.0 & 0.1 & 0.1 & 0.2 & 0.6 & $2 \cdot 4$ \\
\hline Yogurt & 0.0 & 0.1 & 0.5 & 0.1 & 0.1 & $1 \cdot 1$ \\
\hline Cream & 0.0 & 0.0 & 0.0 & 0.0 & 0.0 & 0.0 \\
\hline Cheese & 0.0 & 0.0 & $0 \cdot 1$ & 0.0 & 0.0 & 0.4 \\
\hline Frozen milk products & 0.0 & 0.0 & 0.0 & 0.0 & 0.0 & 0.0 \\
\hline Custards & 0.0 & 0.0 & 0.0 & 0.0 & 0.0 & 0.0 \\
\hline Other milk products & 0.0 & 0.0 & 0.0 & 0.0 & 0.0 & 0.0 \\
\hline Flavoured milks & 0.0 & 0.0 & 0.0 & 0.0 & 0.0 & 0.0 \\
\hline Fruits & 0.2 & 0.2 & $2 \cdot 7$ & 0.6 & 0.4 & 8.5 \\
\hline Vegetables & 0.5 & 0.4 & $5 \cdot 2$ & 0.4 & 0.4 & $6 \cdot 4$ \\
\hline Legumes & 0.1 & 0.2 & 0.8 & 0.1 & 0.4 & $2 \cdot 1$ \\
\hline Others & 0.1 & 0.3 & 1.6 & 0.5 & 0.6 & 7.6 \\
\hline Eggs & 0.0 & 0.1 & 0.3 & $0 \cdot 1$ & 0.2 & 1.4 \\
\hline Nuts and seeds & 0.0 & 0.0 & 0.0 & 0.0 & $0 \cdot 1$ & 0.3 \\
\hline Fruits and vegetable juices & 0.0 & 0.0 & 0.0 & 0.0 & 0.0 & 0.2 \\
\hline Water and mineral waters & 0.0 & 0.0 & 0.1 & 0.0 & 0.0 & 0.6 \\
\hline Non-core extras/miscellaneous itemst† & 0.1 & 0.2 & $1 \cdot 1$ & 0.3 & 0.5 & 5.2 \\
\hline
\end{tabular}

* Mean percentage of Fe contribution from food groups.

$\dagger$ Fe-fortified products.

‡ Fruit juices marketed towards infants and toddlers.

$\S$ Includes unfortified and fortified varieties.

II Flesh from all meats, poultry, game, finfish, crustacea, molluscs and organs.

II Includes sausages, ham, bacon, canned meat and seafood products.

$\star \star$ Dishes in which meat is the predominant ingredient.

†† Tea, cordial, other beverage flavourings and prepared beverages, spreads, herbs, spices, snacks, confectionery.

To examine why toddlers who were introduced to solid foods earlier than 6 months of age had higher Fe intake compared with toddlers introduced to solid foods at or after 6 months, the differences in sex, birth weight, birth length, current weight, current length, breast-feeding status, maternal education, maternal employment status, mother's country of birth, energy intake, Fe density, and Fe intake per kg of body weight were assessed between these two groups by means of the $\chi^{2}$ test or Student's $t$ test as appropriate. The prevalence of inadequate Fe intake was determined for each group using the full probability approach as described above, and the two-sample test of proportions was then used to test for between-group differences in the prevalence of inadequate Fe intakes. There were no differences in sex $(P=0.957)$, breast-feeding status $(P=0 \cdot 178)$, maternal education $(P=0.929)$, maternal employment status $(P=0.593)$ or mother's country of birth $(P=0 \cdot 172)$ between the two groups. Toddlers who were introduced to solid foods before 6 months of age had a greater birth weight (mean difference: $0 \cdot 2 ; 95 \%$ CI $0 \cdot 0,0.3 \mathrm{~kg} ; P=0 \cdot 012$ ), tended to have a greater birth length (mean difference: $0 \cdot 6 ; 95 \%$ CI $0 \cdot 0$, $1.2 \mathrm{~cm} ; P=0.055$ ), were currently heavier (mean difference: 0.4 ; $95 \%$ CI $0.1,0.7 \mathrm{~kg} ; P=0.006$ ), were currently longer (mean 
Table 4. Factors associated with iron intakes

(Mean values and standard deviations)

\begin{tabular}{|c|c|c|c|c|c|c|}
\hline \multirow[b]{3}{*}{ Variables } & \multicolumn{3}{|c|}{ Infants (n 457†) } & \multicolumn{3}{|c|}{ Toddlers (n 372†) } \\
\hline & \multicolumn{3}{|c|}{ Fe intakes } & \multicolumn{3}{|c|}{ Fe intakes } \\
\hline & Mean (mg/d) & SD & $P \ddagger$ & Mean (mg/d) & SD & $P \neq$ \\
\hline \multicolumn{7}{|l|}{ Child characteristics } \\
\hline Sex & & & $0.022^{*}$ & & & 0.139 \\
\hline Male & $9 \cdot 5$ & 4.5 & & $6 \cdot 7$ & $2 \cdot 4$ & \\
\hline Female & $8 \cdot 4$ & $4 \cdot 1$ & & $6 \cdot 3$ & $2 \cdot 2$ & \\
\hline Breast-feeding status & & & $<0.001^{*}$ & & & 0.165 \\
\hline Never breast-fed (formula fed) & $11 \cdot 4$ & $3 \cdot 8$ & & $6 \cdot 1$ & $2 \cdot 2$ & \\
\hline Stopped breast-feeding & $11 \cdot 2$ & $3 \cdot 2$ & & $6 \cdot 6$ & $2 \cdot 4$ & \\
\hline Currently breast-feeding & $6 \cdot 3$ & 3.9 & & 5.9 & $1 \cdot 8$ & \\
\hline Age when introduced to solid foods (months) & & & 0.462 & & & $0.007^{*}$ \\
\hline$<6$ & $9 \cdot 1$ & 4.4 & & $6 \cdot 7$ & $2 \cdot 3$ & \\
\hline$\geq 6$ & $8 \cdot 7$ & $4 \cdot 2$ & & $6 \cdot 1$ & $2 \cdot 4$ & \\
\hline \multicolumn{7}{|l|}{ Maternal characteristics } \\
\hline Age at recruitment (years)§ & & & 0.264 & & & 0.135 \\
\hline$\leq 32 \cdot 2$ & $9 \cdot 2$ & 4.5 & & $6 \cdot 7$ & $2 \cdot 4$ & \\
\hline$>32 \cdot 2$ & $8 \cdot 7$ & $4 \cdot 2$ & & $6 \cdot 3$ & $2 \cdot 2$ & \\
\hline Level of education & & & 0.054 & & & 0.813 \\
\hline Low (syear 12)川 & $9 \cdot 5$ & 3.9 & & $6 \cdot 4$ & 2.5 & \\
\hline Medium (trade/certificate) & $9 \cdot 6$ & 4.4 & & $6 \cdot 6$ & $2 \cdot 6$ & \\
\hline High ( $\geq$ university degree) & $8 \cdot 5$ & 4.4 & & $6 \cdot 6$ & $2 \cdot 2$ & \\
\hline Employment status & & & 0.106 & & & 0.142 \\
\hline Maternity leave/home duties/unemployed & $8 \cdot 7$ & 4.4 & & $6 \cdot 8$ & 2.5 & \\
\hline Employed full-time or part-time/student & 9.5 & $4 \cdot 2$ & & $6 \cdot 4$ & $2 \cdot 2$ & \\
\hline Other & $9 \cdot 8$ & $3 \cdot 7$ & & $7 \cdot 1$ & $2 \cdot 2$ & \\
\hline Country of birth & & & 0.160 & & & $0 \cdot 106$ \\
\hline Australia & $9 \cdot 1$ & 4.4 & & $6 \cdot 4$ & $2 \cdot 3$ & \\
\hline Other & $8 \cdot 4$ & $4 \cdot 1$ & & $7 \cdot 0$ & 2.5 & \\
\hline
\end{tabular}

* Statistically significant.

$\dagger$ Analysis of participants with complete data for all variables only.

$\ddagger P$ values were obtained from univariate linear regression analysis and adjusted for clustering

$\S$ The median age cut-off point for the mothers of toddlers was 32.3 years.

II Up to completion of final year of secondary school.

difference: $0.9 ; 95 \% \mathrm{CI} 0 \cdot 2,1.7 \mathrm{~cm} ; P=0 \cdot 010)$ and had a greater energy intake (mean difference: 323; $95 \%$ CI $142,503 \mathrm{~kJ} / \mathrm{d}$; $P=0.001)$ compared with toddlers who had been introduced to solid foods at or after 6 months. There was no evidence that Fe density $(P=0.503)$ or Fe intake per $\mathrm{kg}$ of body weight $(P=0.137)$ differed between the two groups. Inadequate $\mathrm{Fe}$ intakes were found in $17 \cdot 0$ (95\% CI 12.8, 21.9) \% of toddlers introduced to solid foods before 6 months of age and 22.0 (95\% CI $15 \cdot 2,30 \cdot 8) \%$ of toddlers introduced to solid foods at or after 6 months; there was no evidence that these proportions differed between the two groups $(P=0 \cdot 237)$.

\section{Discussion}

This study examined $\mathrm{Fe}$ intakes, food sources of $\mathrm{Fe}$ and non-dietary predictors of Fe intakes in Australian infants and toddlers. We found that $32.6 \%$ of infants and $18.6 \%$ of toddlers were at risk for inadequate Fe intake. The main food sources of Fe for infants were infant formula, Fe-fortified infant products, and cereals. For toddlers, the main food sources of Fe were cereals, meat/meat products/meat dishes and toddler formula. Female sex and current breast-feeding were negatively associated with infant Fe intake. Introduction to solid foods at or later than 6 months was negatively associated with Fe intake for toddlers.

Although the prevalence of inadequate Fe intake as high as $66 \%$ for infants and toddlers has been observed in other highresource countries ${ }^{(25,39-41)}$, the proportion of Australian infants and toddlers at risk for inadequate $\mathrm{Fe}$ intake has previously been shown to range between 9 and $23 \%^{(5,21,24)}$. This wide range among published studies is likely to be partially due to different methods used to estimate the proportion of children at risk $^{(5,21,22,24,25,39-41)}$. We used the full probability approach, which is recommended for this age group, rather than the estimated average requirement cut-off point method ${ }^{(33)}$. Furthermore, 24-h recall methodology has been shown to potentially overestimate $\mathrm{Fe}$ intakes for this age group ${ }^{(42)}$, and therefore the use of 24-h recalls may have overestimated the children's Fe intakes in our study, hence likely underestimating the prevalence of inadequate intake.

Our findings agree with US studies ${ }^{(39,40)}$ that identify infants to be at greater risk for inadequate Fe intake than toddlers; this is despite higher mean Fe intakes for infants than for toddlers in the present study. Unlike ours and US studies ${ }^{(39,40)}$, others have reported toddlers to be at greater risk for inadequate Fe intake compared with infants ${ }^{(5,21,22,24,25,39-41)}$. A plausible explanation for the high prevalence of inadequate Fe intake for infants in 
our study may be that in Australia Fe intakes of $11 \mathrm{mg}$ for infants over 6 months and $9 \mathrm{mg}$ for toddlers are recommended ${ }^{(36)}$ to compensate for exhausted stores ${ }^{(17)}$ and meet the critical demands of the developing brain ${ }^{(12,43)}$. Furthermore, a higher proportion of infants in our study were currently breast-feeding ( $45.8 \%)$. A previous study of Australian infants, in which the prevalence of inadequate Fe intake was $9 \%$, reported that onethird of infants were currently breast-feeding in their analysis of 1999-2001 data ${ }^{(21)}$. Breast-feeding children were excluded from the New Zealand data, in which $15 \%$ of infants were deemed at risk for inadequate $\mathrm{Fe}$ intake ${ }^{(41)}$. The difficulties of quantifying breast milk volume and feeding time may justify the exclusion of breast-feeding infants in studies on dietary intake. Our study found that children who were breast-feeding at 9 months had the lowest Fe intakes compared with children who had either stopped breast-feeding or had never breast-fed. This is expected as human milk has an Fe concentration of approximately $0.3 \mathrm{mg} / \mathrm{l}^{(44)}$ compared with $5-16 \mathrm{mg} / \mathrm{l}$ required in Australian infant formulae ${ }^{(45)}$ recommended as a breast milk substitute in the first 12 months of life when breast-feeding is not possible ${ }^{(37)}$. In addition, the increased risk for inadequate $\mathrm{Fe}$ intake in toddlers reported by others ${ }^{(5,21,22,24,25,39-41)}$ may be attributed to age-related decline of consumption of Fe-fortified infant/toddler formula. For example, in line with our findings, a recent New Zealand study found that $\mathrm{Fe}$ intake from Fe-fortified formulae contributed $60 \%$ for infants and $0 \%$ for toddlers ${ }^{(41)}$. As toddler diets transition to comprise more family foods, including unmodified cows' milk, their reliance on Fe-fortified formula and products decreases.

While over two-thirds of the children were consuming solid foods before 6 months, up to one-third of infants were at risk for inadequate Fe intake. This suggests that the transitioning diets of Australian infants and toddlers lack sufficient quantities of Fe-rich complementary foods. Indeed, we reported animal tissue intakes of 20.7 and $35.3 \mathrm{~g} / \mathrm{d}$ for infants and toddlers, respectively. This is in line with recent Australian data suggesting that frequency of consumption and quantities of meat are low for young Australian children $^{(20,24)}$. Furthermore, Fe contribution from meat, meat products and meat dishes was minimal in our study, which could be due to a preference for poorer quality meat by children of this age, as suggested by previous research ${ }^{(20,23,46)}$, such as processed meat products. Parents may offer processed meats to their children because of child texture preferences, child dentition, parental lack of skill to prepare other meat to suit the child's developmental stage ${ }^{(19,23)}$, or lack of awareness that processed meats have poorer Fe content ${ }^{(23)}$. Increasing the frequency and quantity of quality Fe sources, such as lean red meat, is a possible strategy for improving Fe intakes for Australian infants and toddlers as this has been shown to positively affect Fe stores in this

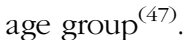

Cereals contributed the majority of Fe for toddlers in our study ( $43.3 \%$ ). Fe contributions from cereals of approximately $30 \%$ have previously been observed in Australian and New Zealand toddler diets ${ }^{(24,41,48)}$. The greater Fe contribution from cereals to toddler diets found in our study is likely because of the increasingly popular practice of Fe fortification to the food supply. The inter- and intra-country discrepancies of dietary patterns and changes in Fe fortification of foods $(23,24,39,40,46,49)$ emphasise the importance of local research into Australian children's Fe intakes and their food sources of Fe.

We found that some infants and as many as one-quarter of toddlers consumed $>500 \mathrm{ml}$ of unmodified cows' milk/d. These results indicate that some Australian infants consume unmodified cows' milk as the main drink. This is of concern because unmodified cows' milk has been associated with Fe deficiency in children under 12 months of age ${ }^{(50)}$. Furthermore, the large quantities of cows' milk consumed by some Australian infants and many toddlers also raise concern because intakes of $>500 \mathrm{ml}$ of cows' milk/d in the first 2 years of life have been associated with substantially lower ferritin concentrations ${ }^{(7,41,51,52)}$. Unmodified cows' milk is a poor source of Fe and is likely to displace potentially Fe-rich foods, such as red meat. Therefore, the Australian Infant Feeding Guidelines recommend that infants are not offered unmodified cows' milk as a main drink until after 12 months of age and that after 12 months of age the consumption of cows' milk should be limited to no more than $500 \mathrm{ml} / \mathrm{d}^{(37)}$.

Toddlers introduced to solid foods at or after 6 months of age had lower Fe intakes than those who were introduced to solid foods earlier than this. It is unlikely that the timing of introduction of complementary foods contributed to this finding in our study. The difference in body size may partially explain this result, as because of the greater body size toddlers who were introduced to solid foods before 6 months of age consumed more energy and, as a result, had greater Fe intakes compared with toddlers who were introduced to solid foods at or after 6 months. However, Fe density and Fe intake per kg of body weight did not differ between these two groups of toddlers. There was also no evidence for a difference in the prevalence of inadequate Fe intakes between the two groups.

Despite international findings indicating an association between toddler Fe intake and maternal education ${ }^{(25)}$, the results of this study did not show this association. This may be due to the over-representation of women with a tertiary education in the sample $\mathrm{e}^{(53)}$.

The study design and validated measures of the InFANT Program $^{(27)}$ strengthened the capacity of this study to provide contemporary, local information in relation to children's Fe intakes. The use of 3 non-consecutive days of comprehensive dietary recall data was a major strength of this study. Dietary recalls are considered the gold standard for dietary intake assessment, especially for large quantitative studies of young children $^{(42,54)}$. Given the reliance on parental-report measures when assessing dietary intakes of children, the potential for social desirability bias and misreporting is a possible limitation. Even so, when considering the potential for overestimation of diet recalls ${ }^{(42)}$, Fe intakes are still alarmingly inadequate for this population. Additionally, we excluded implausibly high or low mean intakes for Fe and energy (more than 3 SD above or below the mean) to exclude potentially inaccurate reports. Although multiple dietary recalls may be burdensome for participants ${ }^{(55)}$, a high retention rate was maintained. This may be explained by the target sample of first-time parents who are likely to be more receptive to promoting healthy family eating and developing parenting skills ${ }^{(28)}$; however, this may limit the generalisability of our results. Finally, although we did not measure Fe status in this 
study, the prevalence of biochemical deficiency in this cohort may be similar to the prevalence of inadequate Fe intakes estimated in the current study as has been shown by others ${ }^{(5,33)}$.

In conclusion, Fe intakes may be inadequate for up to a third of Australian infants and one-fifth of toddlers, despite the consumption of Fe-fortified foods. As late infancy is a period of rapid growth and high $\mathrm{Fe}$ requirements, dietary strategies focusing on improving infants' intakes of Fe are necessary. The introduction of solid foods to infants around 6 months, as per recommendations ${ }^{(37)}$, should be with Fe-rich foods to offset depleted Fe stores. This is particularly important for breast-fed infants. Considering that the Fe contribution from meat in the present study was low, strategies are warranted to increase the sources of lean red meat, given that it is a rich source of Fe of high bioavailability. Adherence to Australian guidelines regarding consumption of unmodified cows' milk as a main drink only after 12 months of age ${ }^{(37)}$ and limiting its intake to no more than $500 \mathrm{ml} / \mathrm{d}$ should also be encouraged. Continued investigation into the dietary patterns of Australian infants and toddlers is recommended in order to improve Fe intakes during this important phase of child growth.

\section{Acknowledgements}

This study was funded by the National Health and Medical Research Council (ID 425801), Heart Foundation Victoria and Deakin University. S. A. M. was supported by an Australian Research Council Future Fellowship (FT100100581).

The authors' responsibilities were as follows: L. A. A. and E. A. S.-G. analysed the data. S. A. M. contributed to data analysis. L. A. A. wrote the initial draft of the manuscript. S. A. M. and K. J. C. designed and managed the dietary data collection. K. J. C. designed and led the Melbourne InFANT Program. E. A. S.-G. designed and oversaw the present study and took primary responsibility for the final content of the manuscript. All authors contributed to the interpretation of results and writing of the manuscript, and read and approved the final version.

None of the authors reported a conflict of interest related to the study.

\section{Supplementary material}

For supplementary material/s referred to in this article, please visit http://dx.doi.org/doi:10.1017/S0007114515004286

\section{References}

1. McLean E, Cogswell M, Egli I, et al. (2009) Worldwide prevalence of anaemia, WHO Vitamin and Mineral Nutrition Information System, 1993-2005. Public Health Nutr 12, 444-454.

2. World Health Organization, United Nations Children's Fund, United Nations University (2001) Iron Deficiency Anaemia: Assessment, Prevention and Control. A Guide for Programme Managers, no. WHO/NHD/01.3. Geneva: WHO.

3. Institute for Health Metrics and Evaluation (2013) Global Burden of Disease Profile: Australia. Seattle, WA: Institute for Health Metrics and Evaluation.
4. Oti-Boateng P, Seshadri R, Petrick S, et al. (1998) Iron status and dietary iron intake of 6-24-month-old children in Adelaide. J Paediatr Child Health 34, 250-253.

5. Zhou SJ, Gibson RA, Gibson RS, et al. (2012) Nutrient intakes and status of preschool children in Adelaide, South Australia. Med J Aust 196, 696-700.

6. Karr M, Alperstein G, Causer J, et al. (1996) Iron status and anaemia in preschool children in Sydney. Aust $N Z J$ Public Health 20, 618-622.

7. Nguyen ND, Allen JR, Peat JK, et al. (2004) Iron status of young Vietnamese children in Australia. J Paediatr Child Health 40, 424-429.

8. Georgieff MK (2011) Long-term brain and behavioral consequences of early iron deficiency. Nutr Rev 69, S43-S48.

9. Rao R \& Georgieff MK (2007) Iron in fetal and neonatal nutrition. Semin Fetal Neonatal Med 12, 54-63.

10. Beard JL (2008) Why iron deficiency is important in infant development. J Nutr 138, 2534-2536.

11. Grantham-McGregor S \& Ani C (2001) A review of studies on the effect of iron deficiency on cognitive development in children. J Nutr 131, 649S-668S.

12. Lozoff B, Beard J, Connor J, et al. (2006) Long-lasting neural and behavioral effects of iron deficiency in infancy. Nutr Rev 64, S34-S43.

13. Lukowski AF, Koss M, Burden MJ, et al. (2010) Iron deficiency in infancy and neurocognitive functioning at 19 years: evidence of long-term deficits in executive function and recognition memory. Nutr Neurosci 13, 54-70.

14. Deinard AS, List A, Lindgren B, et al. (1986) Cognitive deficits in iron-deficient and iron-deficient anemic children. J Pediatr 108, 681-689.

15. Lozoff B \& Georgieff MK (2006) Iron deficiency and brain development. Semin Pediatr Neurol 13, 158-165.

16. McCann JC \& Ames BN (2007) An overview of evidence for a causal relation between iron deficiency during development and deficits in cognitive or behavioral function. Am J Clin Nutr 85, 931-945.

17. Dallman PR (1992) Changing iron needs from birth through adolescence. In Nutritional Anemias, Nestle Nutrition Workshop Series, 30, pp. 29-38 [SJ Fomon and S Zlotkin, editors]. New York: Vevey/Raven Press.

18. Aggett PJ, Agostoni C, Axelsson I, et al. (2002) Iron metabolism and requirements in early childhood: do we know enough?: a commentary by the ESPGHAN Committee on Nutrition. J Pediatr Gastroenterol Nutr 34, 337-345.

19. Hallberg L, Hoppe M, Andersson M, et al. (2003) The role of meat to improve the critical iron balance during weaning. Pediatrics 111, 864-870.

20. Byrne R, Magarey A \& Daniels L (2014) Food and beverage intake in Australian children aged 12-16 months participating in the NOURISH and SAIDI studies. Aust $N$ Z J Public Health 38, 326-331.

21. Conn JA, Davies MJ, Walker RB, et al. (2009) Food and nutrient intakes of 9-month-old infants in Adelaide, Australia. Public Health Nutr 12, 2448-2456.

22. Hitchcock NE, Owles EN \& Gracey M (1982) Dietary energy and nutrient intakes and growth of healthy Australian infants in the first year of life. Nutr Res 2, 13-19.

23. Webb K, Rutishauser I, Katz T, et al. (2005) Meat consumption among 18-month-old children participating in the Childhood Asthma Prevention Study. Nutr Diet 62, 12-20.

24. Webb K, Rutishauser I \& Knezevic N (2008) Foods, nutrients and portions consumed by a sample of Australian children aged 16-24 months. Nutr Diet 65, 56-65. 
25. Bramhagen A-C, Svahn J, Hallström I, et al. (2011) Factors influencing iron nutrition among one-year-old healthy children in Sweden. J Clin Nurs 20, 1887-1894.

26. Gibson SA (1999) Iron intake and iron status of preschool children: associations with breakfast cereals, vitamin C and meat. Public Health Nutr 2, 521-528.

27. Campbell KJ, Lioret S, McNaughton SA, et al. (2013) A parentfocused intervention to reduce infant obesity risk behaviors: a randomized trial. Pediatrics 131, 652-660.

28. Campbell K, Hesketh K, Crawford D, et al. (2008) The Infant Feeding Activity and Nutrition Trial (InFANT) an early intervention to prevent childhood obesity: cluster-randomised controlled trial. BMC Public Health 8, 103-103.

29. World Health Organization (2000) Obesity: Preventing and Managing the Global Epidemic: Report of a WHO Consultation on Obesity. Geneva: WHO.

30. Lioret S, McNaughton SA, Spence AC, et al. (2013) Tracking of dietary intakes in early childhood: the Melbourne InFANT program. Eur J Clin Nutr 67, 275-281.

31. Food Standards Australia New Zealand (2008) AUSNUT 2007 Australian Food, Supplement and Nutrient Database for Estimation of Population Nutrient Intakes. Canberra: FSANZ.

32. Emmett P, North K \& Noble S (2000) Types of drinks consumed by infants at 4 and 8 months of age: a descriptive study. The ALSPAC Study Team. Public Health Nutr 3, 211-217.

33. Food and Nutrition Board: Institute of Medicine (2001) Dietary Reference Intakes for Vitamin A, Vitamin K, Arsenic, Boron, Chromium, Copper, Iodine, Iron, Manganese, Molybdenum, Nickel, Silicon, Vanadium, and Zinc. Washington, DC: National Academy Press.

34. World Health Organization/Food and Agriculture Organization of the United Nations (2006) Guidelines on Food Fortification with Micronutrients. Geneva: WHO.

35. Nusser SM, Carriquiry AL, Dodd KW, et al. (1996) A semiparametric transformation approach to estimating usual daily intake distributions. J Am Stat Assoc 91, 1440-1449.

36. National Health and Medical Research Council (2006) Nutrient Reference Values for Australia and New Zealand Including Recommended Dietary Intakes. Canberra: Commonwealth of Australia.

37. National Health and Medical Research Council (2012) Eat for Health. Infant Feeding Guidelines: Information for Health Workers. Canberra: Commonwealth of Australia.

38. World Health Organization Multicentre Growth Reference Study Group (2006) WHO Child Growth Standards: Methods and Development: Length/Height-for-Age, Weight-for-Age, Weight-for-Length, Weight-for-Height and Body Mass Indexfor-Age. Geneva: WHO

39. Butte NF, Fox MK, Briefel RR, et al. (2010) Nutrient intakes of US infants, toddlers, and preschoolers meet or exceed dietary reference intakes. J Am Diet Assoc 110, S27-S37.
40. Devaney B, Ziegler P, Pac S, et al. (2004) Nutrient intakes of infants and toddlers. J Am Diet Assoc 104, SS14-SS21.

41. Soh P, Ferguson EL, McKenzie JE, et al. (2002) Dietary intakes of 6-24-month-old urban South Island New Zealand children in relation to biochemical iron status. Public Health Nutr $\mathbf{5}, 339-346$.

42. Fisher JO, Butte NF, Mendoza PM, et al. (2008) Overestimation of infant and toddler energy intake by 24 -h recall compared with weighed food records. Am J Clin Nutr 88, 407-415.

43. Gordon N (2003) Iron deficiency and the intellect. Brain Dev 25, 3-8.

44. Butte NF, Lopez-Alarcon MG \& Garza C (2002) Nutrient Adequacy of Exclusive Breastfeeding for the Term Infant During the First Six Months of Life. Geneva: WHO.

45. Food Standards Australia New Zealand (2014) Standard 2.9.1 - infant formula products. http://www.comlaw.gov.au/ Details/F2014C01200 (accessed April 2015)

46. Fox MK, Pac S, Devaney B, et al. (2004) Feeding infants and toddlers study: what foods are infants and toddlers eating? $J$ Am Diet Assoc 104, S22-S30.

47. Szymlek-Gay EA, Ferguson EL, Heath AL, et al. (2009) Foodbased strategies improve iron status in toddlers: a randomized controlled trial. Am J Clin Nutr 90, 1541-1551.

48. Szymlek-Gay EA, Ferguson EL, Heath AM, et al. (2010) Quantities of foods consumed by 12- to 24-month-old New Zealand children. Nutr Diet 67, 244-250.

49. Scientific Advisory Committee on Nutrition (2010) Iron and Health. London: TSO.

50. Thorsdottir I, Gunnarsson B, Atladottir H, et al. (2003) Iron status at 12 months of age-effects of body size, growth and diet in a population with high birth weight. Eur J Clin Nutr $\mathbf{5 7}, 505-513$

51. Thane CW, Walmsley CM, Bates CJ, et al. (2000) Risk factors for poor iron status in British toddlers: further analysis of data from the national diet and nutrition survey of children aged 1.5-4.5 years. Public Health Nutr 3, 433-440.

52. Gunnarsson BS, Thorsdottir I, Palsson G, et al. (2007) Iron status at 1 and 6 years versus developmental scores at 6 years in a well-nourished affluent population. Acta Paediatr 96, 391-395.

53. Spence AC, McNaughton SA, Lioret S, et al. (2013) A health promotion intervention can affect diet quality in early childhood. J Nutr 143, 1672-1678.

54. Biró G, Hulshof KF, Ovesen L, et al. (2002) Selection of methodology to assess food intake. Eur J Clin Nutr $\mathbf{5 6}$, S25-S32.

55. Magarey A, Watson J, Golley RK, et al. (2011) Assessing dietary intake in children and adolescents: considerations and recommendations for obesity research. Int I Pediatr Obes 6, $2-11$. 